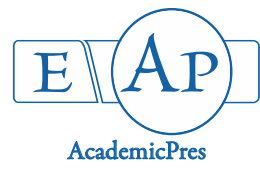

\title{
Differential Activity of Antioxidant Enzymes and Physiological Changes in Wheat (Triticum aestivum L.) Under Drought Stress
}

\author{
Kamal MIRI-HESAR, Ali DADKHODAIE*, Saeideh DOROSTKAR, \\ Bahram HEIDARI
}

\author{
Shiraz University, School of Agriculture, Department of Crop Production and Plant Breeding, Shiraz, Iran; khabat.miri.1365@gmail.com \\ dadkhodaie@shirazu.ac.ir ('correspondingauthor); saeideh.dorostkar@gmail.com; bheidari@shirazu.ac.ir
}

\begin{abstract}
Drought stress is one of the most significant environmental factors restricting plant production all over the world. In arid and semi-arid regions where drought often causes serious problems, wheat is usually grown as a major crop and faces water stress. In order to study drought tolerance of wheat, an experiment with 34 genotypes including 11 local and commercial cultivars, 17 landraces, and six genotypes from International Maize and Wheat Improvement Center (CIMMYT) was conducted at the experimental station, School of Agriculture, Shiraz University, Iran in 2010-2011 growing season. Three different irrigation regimes (100\%, 75\% and 50\% Field Capacity) were applied and physiological and biochemical traits were measured for which a significant difference was observed in genotypes. Under severe water stress, proline content and enzymes' activities increased while the relative water content (RWC) and chlorophyll index decreased significantly in all genotypes. Of these indices, superoxide dismutase (SOD) and RWC were able to distinguish tolerant genotypes from sensitives. Moreover, yield index (YI) was useful in detecting tolerant genotypes. The drought susceptibility index (DSI) varied from 0.40 to 1.71 in genotypes. These results indicated that drought-tolerant genotypes could be selected based on high YI, RWC and SOD and low DSI. On the whole, the genotypes 31 (30ESWYT200), 29 (30ESWYT173) and 25 (Akbari) were identified to be tolerant and could be further used in downstream breeding programs for the improvement of wheat tolerance under water limited conditions.
\end{abstract}

Keywords: antioxidant enzymes; drought stress; grain yield; landraces; wheat

\section{Introduction}

Drought stress is known to be the most important environmental factor that limits plant's growth and production (Kirigwi et al., 2004; Almeselmani et al., 2011) and has been a great threat to wheat production worldwide. For example, in 1999, about $9 \mathrm{mt}$ wheat grains was harvested from an area of $6.5 \mathrm{~m}$ ha in Iran, which increased to $15 \mathrm{mt}$ in 2005, but decreased to $11 \mathrm{mt}$ in 2016 predominantly due to the dwindling water resources and increasing drought intensity (FAO STAT, 2017). Accordingly, it is vital to understand wheat's response to drought stress throughout growth stages to mitigate its detrimental effects.

Drought stress responses are altered by changes in the expression level of various compatible solutes/osmolytes and the reactive oxygen species (ROS), which in turn affect plant at morphological, physiological and biochemical levels (Shinozaki et al., 2007; Sheoran et al., 2013). Moderate to severe stresses drastically affects wheat's various physiological traits such as relative water content (RWC), chlorophyll content and chlorophyll fluorescence. Therefore, chances are there that genotypes may respond differentially under moderate to severe water stress at a similar growth stage. Also, during drought stress, plant water relations play a key role in the activation and/or modulation of the antioxidant defense mechanism (De Carvalho, 2008). The elimination of $\mathrm{O}_{2}{ }^{-}$by superoxide dismutase (SOD) generates $\mathrm{H}_{2} \mathrm{O}_{2}$, which is removed by catalase (CAT) and peroxidase (POX) (Bartosz, 1997). A number of studies have indicated that higher activity levels of antioxidant enzymes contribute to better drought tolerance in wheat through increasing its protection capacity against oxidative damage (Sairam et al., 1997; Almeselmani et al., 2006). However, change in activities of antioxidant enzymes under drought stress depends on plant species, genotype and stress intensity and duration (DaCosta and Huang, 2007). 
Understanding the association of antioxidant enzyme activity, physiological responses and variation in drought tolerance of genotypes is important to further decipher factors that control plant defense. Iran, with more than 50\% of its agricultural land allocated to wheat production, suffers from low rainfall and consequently, grain yield shows a significant fluctuation in consecutive years. At the same time, it benefits from a rich germplasm compatible to local conditions. Despite this, the genetic resources have been underutilized. Therefore, the present study was conducted to evaluate the physiological traits and antioxidant responses of wheat landraces and some other genotypes under drought stress, at different levels of irrigation. Our hypothesis is that water stress at different levels can change the physiological and biochemical responses of plants and some genotypes may display higher tolerance.

\section{Materials and Methods}

\section{Plantmaterials}

Thirty-four wheat genotypes including eight commercial cultivars ('Arvand', 'Karaj3', 'Darab2', 'Khazar1', 'Sepahan', 'Shiraz', 'Cross Boolani' and 'Bezostaya'), six CIMMYT- derived lines ( $30^{\text {th }}$ Elite Spring Wheat Yield Trials released by International Maize and Wheat Improvement Center (CIMMYT) in 2011) and twenty landraces consisting of 'Shahani', 'Hawasi', 'Akbari' and ' $17 \mathrm{KC}$ '-designated genotypes were used in current study (Table 1). Field evaluations were performed at the research station $\left(52^{\circ} 32^{\prime} \mathrm{E}\right.$ and $29^{\circ} 36^{\prime} \mathrm{N}, 1810 \mathrm{~m}$ above sea level), School of Agriculture, Shiraz University, Iran.

\section{Experimental design and field evaluations}

267

The experimental frame was as a split-plot design where irrigation regimes (100\% field capacity (FC), $75 \%$ FC and $50 \% \mathrm{FC}$ ) were used in larger main plots in a randomized complete block design with three replications and genotypes were allocated to smaller sub-plots. The soil was silty clay in which the percentages of silt, clay and sand in the depth of $0-30 \mathrm{~cm}$ soil profile were $42.72 \%, 52 \%$ and $5.28 \%$, respectively. The electrical conductivity of the soil was 0.395 $\mathrm{dS} \mathrm{m}^{-1}$ with $\mathrm{pH}$ 7.8. The genotypes were planted in four 2.5 -meter-long rows with a density of 300 seeds $\mathrm{m}^{-2}$. An amount of $110 \mathrm{~kg} \mathrm{ha}^{-1}$ urea fertilizer (46\% nitrogen) was distributed at planting and ear emergence stages. Drought stress was applied based on field capacity and the amount of water per irrigation was determined based on soil moisture content as below.

$$
\begin{aligned}
& d_{n}=\frac{\left(F_{c}-\theta_{m}\right) \rho_{b} * D}{100} \\
& \theta_{m}=\frac{F W-D W}{D W}
\end{aligned}
$$

where:

$\mathrm{Fc}_{\mathrm{c}}$ is field capacity, $\mathrm{dn}$ is height of required water for irrigation, $\theta \mathrm{m}$ is soil moisture content, $p \mathrm{~b}$ is soil apparent density, D is depth of soil sampling, FW and DW are fresh and dried weights of soil, respectively (Zimmerman, 2002). Weather information for the experimental site is given in Table 2. Samples for measuring grain yield, thousand kernel weight (TKW) and plant height were taken from the middle rows at physiological maturity leaving $50 \mathrm{~cm}$ either side as border.

\begin{tabular}{|c|c|c|c|c|c|c|c|c|}
\hline code & Genotype & Origin & Code & Genotype & Origin & Code & Genotype & Origin \\
\hline 1 & 'Arvand' & Iran & 13 & KC136 & Iran & 25 & Akbari & Iran \\
\hline 2 & 'Karaj3’ & Iran & 14 & KC184 & Iran & 26 & 30ESWYT105 & CIMMYT \\
\hline 3 & 'Darab2' & Iran & 15 & KC29 & Iran & 27 & 30ESWYT 120 & CIMMYT \\
\hline 4 & 'Khazarl' & Iran & 16 & KC68 & Iran & 28 & 30ESWYT160 & CIMMYT \\
\hline 5 & 'Sepahan' & Iran & 17 & KC201 & Iran & 29 & 30ESWYT173 & CIMMYT \\
\hline 6 & 'KC185' & Iran & 18 & KC219 & Iran & 30 & 30ESWYT184 & CIMMYT \\
\hline 7 & 'KC161' & Iran & 19 & $\mathrm{KC} 50$ & Iran & 31 & 30ESWYT200 & CIMMYT \\
\hline 8 & ‘KC41’ & Iran & 20 & KC211 & Iran & 32 & Shiraz & Iran \\
\hline 9 & 'KC187’ & Iran & 21 & KC227 & Iran & 33 & Cross Boolani & Iran \\
\hline 10 & 'KC132' & Iran & 22 & KC91 & Iran & 34 & Bezostaya & Iran \\
\hline 11 & 'KC174' & Iran & 23 & Shahani & Iran & & & \\
\hline 12 & ‘КC99’ & Iran & 24 & Hawasi & Iran & & & \\
\hline
\end{tabular}

Table 1. List of 34 hexaploid wheat genotypes (landraces and cultivars) used to evaluate drought stress response

The genotypes preceded by KC, were obtained from Seed and Plant Improvement Research Institute in Karaj, Iran. Genotypes designated with ESWYT are from $30^{\text {th }}$ Elite Spring Wheat Yield Trials released by International Maize and Wheat Improvement Center (CIMMYT) in 2011

\begin{tabular}{|c|c|c|c|c|}
\hline \multirow{2}{*}{ Month } & \multicolumn{2}{|c|}{ Temperature $\left({ }^{\circ} \mathrm{C}\right)$} & \multirow{2}{*}{ Relative humidity (\%) } & \multirow{2}{*}{ Precipitation $(\mathrm{mm})$} \\
\hline & Minimum & Maximum & & \\
\hline November & -6.94 & 18.20 & 30.85 & 0.00 \\
\hline December & -5.79 & 12.30 & 42.93 & 48.5 \\
\hline January & -1.30 & 10.26 & 48.98 & 107.5 \\
\hline February & 0.89 & 16.27 & 49.47 & 76.8 \\
\hline March & 3.32 & 20.31 & 50.02 & 30.5 \\
\hline April & 7.83 & 27.50 & 48.27 & 0.00 \\
\hline May & 12.39 & 34.10 & 24.47 & 0.00 \\
\hline June & 15.30 & 35.77 & 20.92 & 0.00 \\
\hline Total & - & - & - & 263.3 \\
\hline
\end{tabular}

Table 2. Some weather parameters for the experimental site in 2010-2011 growing season 
268

\section{Physiological traits}

Determination of relative water content $(R W C)$

The relative water content in flag leaves was measured using twenty randomly-chosen fully expanded leaves based on the following formula, where FW is fresh weight, TW and DW are their turgid and dry weights, respectively (turgid weight was measured when leaves were put in distilled water for 16-18 hours while their dry weight was measured after being oven-dried at $70{ }^{\circ} \mathrm{C}$ for 72 hours (Schonfeld et al., 1988).

$$
\mathrm{RWC}=\left[\left(\frac{F W-D W}{T W-D W}\right)\right] \times 100
$$

\section{Chlorophyll content}

Chlorophylls a, b and total chlorophyll were calculated based on Lichtenthaler and Wellburn method (1983). According to this method, $25 \mathrm{~g}$ of flag leaf tissue was homogenized using $5 \mathrm{ml} 80 \%$ acetone. Then the absorption was read at $\lambda=663$ and $646 \mathrm{~nm}$ with spectrophotometer (S2100 Diode Array model, WPA, UK). The amount of chlorophyll was calculated using the following formulas:

Chl a $=(12.25$ A663 - 2.79 A646)

$\mathrm{Chl} b=(21.21 \mathrm{~A} 646-5.1 \mathrm{~A} 663)$

$\mathrm{Chll}=\mathrm{Chl} \mathrm{a}+\mathrm{Chl} \mathrm{b}$

\section{Yield traits and drought index}

Plant height in a sample of 10 plants was measured from the soil surface to the tip of the spike, excluding awns. Plants were harvested at physiological maturity and TKW and grain yield were measured using an electric balance. The drought susceptibility index (DSI) and yield stability were calculated as follows:

$$
\begin{gathered}
\text { DSI }=\left(1-Y_{D} / Y\right)-\left(1-\bar{X}_{D} / \bar{X}\right) \quad \text { (Fischer and } \\
\text { Maurer, 1978) } \\
\text { YSI }=\left(Y_{D} \mid Y\right) \quad \text { (Bouslama and Schapaugh, 1984) }
\end{gathered}
$$

$\mathrm{YD}$ and $\mathrm{Y}$ are the grain yield for each genotype under water stress and control, respectively. $\bar{X} \mathrm{D}$ and $\bar{X}$ are mean grain yield of all genotypes under water stress and control, respectively.

\section{Enzyme extraction and determination of their activities}

To extract enzymes, $0.5 \mathrm{~g}$ of fresh tissue was homogenized in $2 \mathrm{ml}$ buffer ( $\mathrm{pH}=7.8$ ), consisted of $0.607 \mathrm{~g}$ Tris, $0.05 \mathrm{~g}$ PVP (polyvinylpyrrolidone) and $50 \mathrm{ml}$ water. Then, the homogenate was transferred to a new tube and centrifuged at $13000 \mathrm{rpm}$ for $15 \mathrm{~min}$ at $4{ }^{\circ} \mathrm{C}$. Finally, the supernatant was used for the spectrophotometric assay of different antioxidant enzymes (Sairam and Saxena, 2000; Sairam and Srivastava, 2001).

Superoxide Dismutase (SOD) was measured based on its ability to stop light reviving of NBT in the presence of riboflavin and light using Beauchamp and Fridovich method (1971). The concentration of peroxidase (POX) activity was determined based on guaiacol oxidation using the method described by Chance and Maehly (1995). Catalase (CAT) activity was determined based on the consumption of $\mathrm{H}_{2} \mathrm{O}_{2}$ as described by Rao et al. (1996).

\section{Proline content}

Proline concentration was measured following the method by Bates et al. (1973). Five $\mathrm{ml}$ sulfosalicylic acid (3\%) was added to $0.5 \mathrm{~g}$ frozen leaf tissue homogenized and passed through filter paper. Then two $\mathrm{ml}$ of this solution was mixed with an equivalent volume of ninhydrine (consisting of $1.25 \mathrm{~g}$ ninhydrine (Sigma-Aldrich, USA), 30 $\mathrm{ml}$ acetic acid and $20 \mathrm{ml} 6 \mathrm{M}$ phosphoric acid) and two $\mathrm{ml}$ acetic acid. Samples were placed in water bath at $100^{\circ} \mathrm{C}$ for one hour, after which were incubated in cold water for 15 minutes. Following this, four $\mathrm{ml}$ toluene was applied to each tube. Two hours later, two phases formed, of which the liquid phase was used to measure proline concentration at $\lambda=520 \mathrm{~nm}$ with a spectrophotometer (S2100 Diode Array model, WPA, UK). Proline concentration was calculated using the following formula:

$$
\text { Proline }\left(\mu \mathrm{M} \mathrm{g}^{-1} \text { fresh } w \mathrm{t} .\right)=\frac{\mathrm{M} \times \mathrm{T} \times \mathrm{W}}{115.5}
$$

Where $\mathrm{M}$ is the value shown for each sample by the spectrophotometer, $\mathrm{T}$ is toluene volume $(\mathrm{ml})$ and $\mathrm{W}$ is tissue weight $(\mathrm{g})$.

\section{Statistical analysis}

Experimental data were analyzed using SAS (SAS, 2004) and MINITAB software and mean comparison was performed using LSD test at 5\% probability level. The Excel software was used to draw graphs and diagrams.

\section{Results and Discussion}

\section{Relative water content}

Significant differences for genotype and irrigation were observed with respect to RWC (Table 3). Overall, genotypes' RWC changed from $83.1 \%$ under normal condition to $58.9 \%$ under $75 \% \mathrm{FC}$ and $54.2 \%$ under $50 \%$ FC treatments in all thirty-four genotypes, the latter showing higher reduction (Fig. 1). The highest and lowest RWC contents belonged to genotypes number $20,8,2$ and $29,25,5,3$ under normal condition, genotypes 28, 24, 19, 1 and $22,21,17$ under $75 \% \mathrm{FC}$ drought stress, and genotypes 28, 24, 19 and 33, 22, 13, 2 under 50\% FC drought stress, respectively. Results showed that some genotypes maintained relatively higher RWC compared to others under both treatments (50\% and 75\% FC). The genotypes of former group were found to have low DSI and high YI and therefore were drought tolerant. Conversely, genotypes with high DSI and low YI were sensitive to drought. This indicates that RWC as a primary trait responding to drought reduces significantly in sensitive genotypes compared to tolerant genotypes. Variation in RWC also may be attributed to differences in the ability of a genotype to absorb more water from the soil and/or to control water loss through the stomata (Keyvan, 2010). This trait as an indicator of cell water status has been shown to be significantly associated with yield and stress tolerance (Almeselmani et al., 2006; 2011).

\section{Chlorophyll index}

Total chlorophyll content reduced significantly in all genotypes under drought stress (Table 4). 
Table 3. Statistical significance of the source of variations in analysis of variance for RWC of 36 hexaploid wheat genotypes under non-stress (NS, $100 \%$ FC) and stress (75 and 50\% FC) conditions

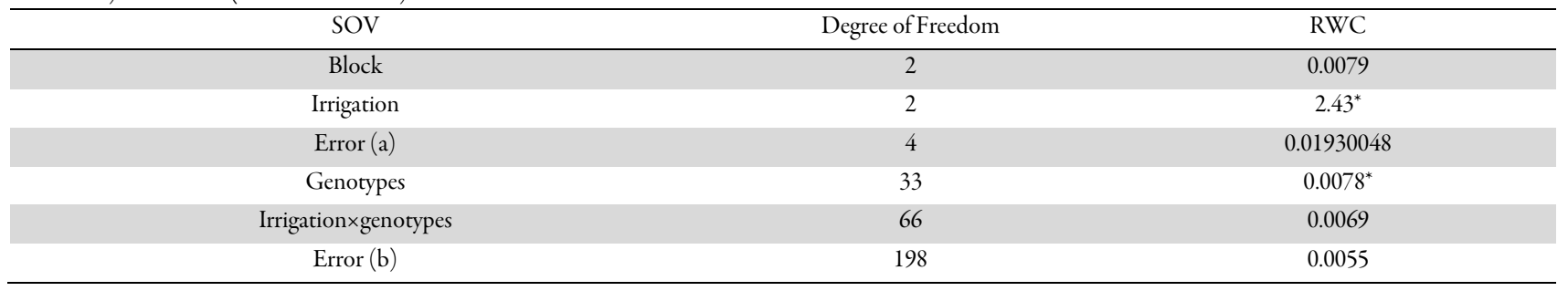

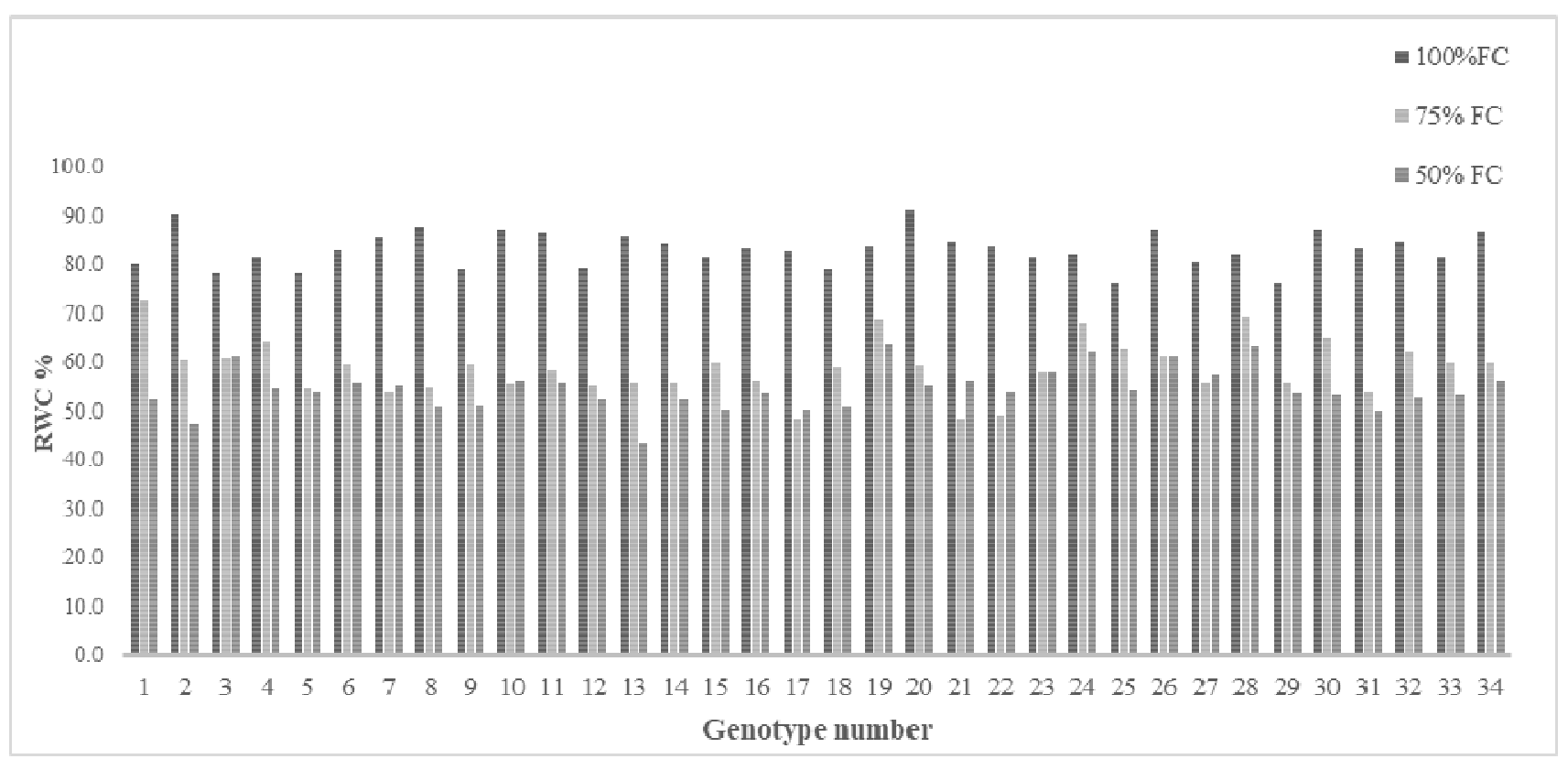

Fig. 1. Relative water content (RWC) in thirty-four hexaploid wheat genotypes under normal and stress irrigation (75 and $50 \%$ field capacity) conditions. ( $\mathrm{LSD}_{5 \%}=12.1$ )

Under normal condition, the highest total chlorophyll content belonged to genotypes 32 and 27, while the lowest amount was detected in genotypes 22, 21 and 6. Under 75\% FC drought condition, the highest and lowest total chlorophyll content belonged to genotypes 34, 24, 3, and $22,12,6$, respectively. Under $50 \%$ FC drought, genotypes $34,31,30,25,3,2$ and 1 showed the highest content whereas genotypes 32,17 and 6 had the lowest total chlorophyll content. The amount of chlorophyll reduction in some genotypes was lower (for example $35 \%$ in genotype 34) while others experienced higher reduction (64\% reduction in genotype 32). The former genotype was found to be tolerant while the latter was sensitive to drought stress. It has been shown that chlorophyll loss is associated with environmental stress, and higher chlorophyll/carotenoids ratio might be a good indicator of stress tolerance in plants (Hendry and Price, 1993). Many previous studies have reported that wheat tolerant genotypes have higher chlorophyll content and predominantly experience lower chlorophyll reduction under stress (Castrillo and Calcargo, 1989; Sairam et al., 1997; Nyachiro et al., 2001). This clearly shows that maintaining chlorophyll concentration under stress conditions is a strategy that plants undertake to overcome drought stress and helps them to stabilize photosynthesis. For this reason, this trait has been successfully employed by many researchers to screen and select for drought tolerant wheat genotypes (Castrillo and Calcargo, 1989; Almeselmani et al., 2011).

Similar to total chlorophyll, drought stress also caused a significant reduction in both chlorophyll a and chlorophyll b contents. This reduction in tolerant genotypes, however, was lower than sensitive ones. Genotypes with high chlorophyll content under higher water stress conditions also had higher yields (Table 5) which was reflected by a significant correlation between chlorophyll index and yield. Similar results reported by Sheoran et al. (2015) showed that high chlorophyll content and its lower reduction could be used as index to select for tolerant genotypes. They also concluded high chlorophyll $\mathrm{a}$ and $\mathrm{b}$ contents under both stress and non-stress could stabilize photosynthesis.

\section{Plant height}

Basically, plant height is a hereditary trait related to plant maturity. In this regard, late-matured genotypes mostly have higher height compared to early-matured ones (Mittler, 2006). According to the results, plant height decreased significantly under drought stress (Table 5). The CIMMYT-derived genotypes i.e 26, 27, 28, 29 and 30 had significantly lower height than other ones under both normal and stress conditions. Taller genotypes (6 and 9) had a significant reduction in height in comparison with shorter ones (29 and 34). 
270

Table 4. Photosynthetic pigments; chlorophylls a, b and total $\left(\mathrm{mg} \mathrm{g}^{-1} \mathrm{FW}\right)$ for thirty-four wheat genotypes under different water deficit regimes and their corresponding $\mathrm{LSD}_{5 \%}$ values

\begin{tabular}{|c|c|c|c|c|c|c|c|c|c|}
\hline \multirow{2}{*}{$\begin{array}{c}\text { Genotype } \\
\text { code }\end{array}$} & \multicolumn{3}{|c|}{ Chlorophyll a } & \multicolumn{3}{|c|}{ Chlorophyll b } & \multicolumn{3}{|c|}{ Total chlorophyll } \\
\hline & $100 \% \mathrm{FC}$ & $75 \% \mathrm{FC}$ & $50 \% \mathrm{FC}$ & $100 \% \mathrm{FC}$ & $75 \% \mathrm{FC}$ & $50 \% \mathrm{FC}$ & $100 \% \mathrm{FC}$ & $75 \% \mathrm{FC}$ & $50 \% \mathrm{FC}$ \\
\hline 1 & 12.47 & 11.79 & 9.86 & 6.86 & 6.21 & 4.82 & 18.32 & 18.00 & 14.68 \\
\hline 2 & 11.60 & 10.81 & 10.39 & 7.54 & 4.65 & 4.23 & 25.14 & 15.46 & 14.62 \\
\hline 3 & 13.55 & 12.22 & 9.68 & 6.30 & 6.28 & 5.21 & 19.86 & 18.50 & 14.89 \\
\hline 4 & 9.49 & 9.14 & 8.32 & 5.33 & 4.18 & 3.86 & 14.82 & 13.33 & 12.18 \\
\hline 5 & 10.95 & 8.52 & 5.77 & 5.65 & 3.32 & 3.35 & 15.60 & 11.84 & 9.11 \\
\hline 6 & 9.55 & 8.18 & 5.75 & 4.61 & 3.43 & 2.27 & 14.16 & 11.61 & 8.02 \\
\hline 7 & 12.81 & 10.53 & 8.37 & 8.00 & 5.18 & 4.07 & 20.80 & 15.72 & 12.45 \\
\hline 8 & 11.90 & 9.94 & 9.74 & 5.20 & 4.25 & 4.20 & 17.10 & 14.19 & 13.94 \\
\hline 9 & 10.68 & 9.69 & 7.07 & 7.03 & 5.61 & 2.82 & 17.71 & 15.30 & 9.89 \\
\hline 10 & 11.02 & 10.78 & 7.54 & 5.73 & 4.75 & 4.40 & 16.75 & 15.52 & 11.94 \\
\hline 11 & 11.99 & 9.43 & 7.48 & 6.66 & 3.86 & 3.20 & 18.65 & 13.30 & 10.68 \\
\hline 12 & 9.11 & 5.21 & 5.57 & 3.86 & 3.63 & 2.84 & 12.98 & 8.84 & 8.41 \\
\hline 13 & 12.33 & 10.94 & 7.87 & 7.23 & 5.10 & 4.19 & 19.56 & 16.04 & 12.06 \\
\hline 14 & 13.79 & 10.53 & 9.43 & 5.81 & 5.31 & 4.77 & 19.60 & 15.84 & 14.20 \\
\hline 15 & 10.99 & 10.07 & 9.34 & 7.91 & 5.23 & 4.52 & 18.90 & 15.30 & 13.85 \\
\hline 16 & 12.01 & 10.08 & 6.66 & 7.51 & 5.79 & 3.41 & 19.51 & 15.88 & 10.07 \\
\hline 17 & 12.46 & 12.08 & 6.60 & 5.67 & 4.73 & 3.38 & 18.13 & 16.80 & 9.99 \\
\hline 18 & 10.37 & 4.90 & 9.25 & 5.02 & 3.97 & 3.64 & 15.39 & 8.87 & 12.89 \\
\hline 19 & 12.27 & 9.98 & 8.73 & 5.97 & 4.68 & 3.55 & 18.24 & 14.66 & 12.28 \\
\hline 20 & 11.89 & 9.89 & 9.63 & 5.26 & 4.57 & 3.87 & 17.15 & 14.46 & 13.50 \\
\hline 21 & 9.61 & 8.72 & 7.56 & 4.94 & 3.44 & 3.49 & 14.55 & 12.16 & 11.05 \\
\hline 22 & 10.07 & 8.28 & 7.33 & 4.46 & 3.33 & 3.12 & 14.53 & 11.61 & 10.45 \\
\hline 23 & 11.10 & 10.79 & 5.46 & 6.29 & 4.58 & 3.60 & 17.39 & 15.37 & 07.9 \\
\hline 24 & 13.08 & 10.63 & 8.64 & 8.80 & 5.54 & 3.84 & 21.88 & 16.17 & 12.49 \\
\hline 25 & 10.33 & 9.18 & 8.3 & 4.70 & 4.80 & 4.48 & 15.02 & 14.61 & 12.51 \\
\hline 26 & 11.64 & 10.44 & 9.36 & 5.88 & 4.30 & 3.87 & 17.52 & 14.74 & 13.23 \\
\hline 27 & 14.14 & 10.87 & 7.79 & 8.83 & 5.18 & 2.49 & 22.97 & 15.06 & 12.46 \\
\hline 28 & 11.81 & 9.69 & 8.75 & 5.15 & 4.10 & 3.64 & 16.95 & 13.79 & 12.39 \\
\hline 29 & 12.89 & 7.89 & 6.82 & 6.62 & 5.35 & 3.37 & 19.52 & 13.24 & 10.55 \\
\hline 30 & 10.72 & 10.32 & 9.89 & 6.74 & 5.91 & 3.97 & 17.45 & 16.23 & 13.86 \\
\hline 31 & 13.59 & 10.17 & 9.61 & 5.33 & 4.35 & 4.03 & 18.93 & 14.53 & 13.64 \\
\hline 32 & 13.47 & 7.49 & 5.36 & 7.18 & 5.44 & 3.14 & 20.66 & 12.93 & 8.50 \\
\hline 33 & 15.14 & 10.31 & 7.29 & 7.04 & 5.15 & 4.32 & 22.17 & 15.47 & 11.60 \\
\hline 34 & 12.54 & 11.01 & 8.42 & 6.73 & 5.69 & 3.97 & 19.27 & 16.70 & 12.40 \\
\hline LSD (5\%) & & 2.595 & & & 1.108 & & & 3.745 & \\
\hline
\end{tabular}

FW: Fresh weight, FC: field capacity, LSD: Least significant difference.

These two genotypes were also shorter than sensitive ones under non-stress conditions. Genotypes 24 and 25 had lower height reduction most likely because water limitation led to food source restriction and therefore plants were forced to slow down their vegetative growth and consequently enter into reproductive phase. As a result, characters such as plant height, growth period, etc decrease. Such a mechanism known as drought escape (Mitra, 2001) which also includes rapid phenological development (flowering and early maturity), developmental flexibility and remobilization of assimilate to grains before flowering, has a dominant effect on plant's adaptation to the environment for maximum production (Passioura, 2007).

\section{Thousand kernel weight}

Applying water stress at different levels showed a significant effect on TKW of genotypes as an important grain yield component (Table 5). Under normal condition, the highest and lowest TKW belonged to genotypes 30 (41.83 g), $28(44.51 \mathrm{~g}), 23(41.65 \mathrm{~g}), 20(46.18 \mathrm{~g}), 16$ (43.08 g), $7(43.3 \mathrm{~g})$ and $15(35.05 \mathrm{~g}), 13(34.05 \mathrm{~g}), 12(33.98 \mathrm{~g}), 2$ (33.43 g), 9 ( $29.15 \mathrm{~g})$, respectively. When $75 \%$ FC water stress was imposed, the genotypes 29,23,21,20, 16 and 5 with $36.73,34.5,35.06,37.56,34.58$ and $35.11 \mathrm{~g}$ had the highest TKW while genotypes 33, 32, 9, 8, 2 and 1 with $30.88,31.13,27.68,29.01,31$ and $28.51 \mathrm{~g}$ had the lowest TKW. At 50\% FC water stress, the highest and lowest amounts of TKW belonged to genotypes 34, 28, 23, 19, 6 $(32.63,31.75,31.45,34.38,33.01 \mathrm{~g})$ and $18,12,10,1$ $(26.61,25.56,24.31,24.3 \mathrm{~g})$, respectively. TKW reduction in response to drought stress indicates that the photosynthetic materials' supply cannot keep with the demand to fill grains under these conditions. Such patterns were also found in studies by Saini and Westgate (2000); Dorostkar et al. (2015) and Sheoran et al. (2015) who reported significant effects of drought stress on TKW of 
wheat genotypes which mainly related to their sensitivity or tolerance to stress. Moreover, decreased kernel weight could be a consequence of low water supply and soluble carbohydrates and a reduction in the number of endoplast cells and amyloplasts in grain (Saini and Westgate, 2000).

It seems that under stress conditions and short supply of photosynthetic materials, the balance between source and sink is maintained through lower seed number and as a result, the remaining grains in the spike gain higher weight. Otherwise, under these photosynthetically restricted conditions, increase in seed number will be accompanied by a reduction in seed weight and will not result in improved grain yield. González et al. (1999) also reported a lack of correlation between seed number per spike and grain yield under drought stress conditions. Similarly, it has been reported that a significant proportion of grain weight during the grain filling period is obtained from the current photosynthesis (Emam and NikNejad, 1994) and hence, decrease in moisture content reduces the current photosynthesis and as a result, seed weight decreases (Ehdaie et al., 2008).

\section{Grain yield and yield stability}

Grain yield per plant reduced significantly in all genotypes (Table 5). Under normal conditions, the highest grain yield belonged to genotypes $32\left(7961 \mathrm{~kg} \mathrm{ha}^{-1}\right), 30$ $\left(8287.17 \mathrm{~kg} \mathrm{ha}^{-1}\right)$ and $27\left(8173 \mathrm{~kg} \mathrm{ha}^{-1}\right)$ and the lowest grain yield related to genotypes $10\left(4515.03 \mathrm{~kg} \mathrm{ha}^{-1}\right), 9$ (4205.02 $\left.\mathrm{kg} \mathrm{ha}{ }^{-1}\right)$ and $4\left(4873.5 \mathrm{~kg} \mathrm{ha}^{-1}\right)$, respectively. In $75 \%$ FC condition, genotypes $34,33,30$ and 29 had the highest grain yield (5899.5, 6156, 6903.3 and $5765.07 \mathrm{~kg} \mathrm{ha}^{-1}$, respectively) and genotypes 28,16 and 9 produced the lowest yield (5595.5, 3698.67 and $3733.5 \mathrm{~kg} \mathrm{ha}^{-1}$, respectively). In 50\% FC, the highest (5148.17, 4908.33, $5283.67,5810.83,5333.83,4686.67,4080.85 \mathrm{~kg} \mathrm{ha}^{-1}$, respectively) and lowest $\left(3218.83,2979.83,2873.75 \mathrm{~kg} \mathrm{ha}^{-1}\right.$, respectively) grain yield belonged to genotypes $34,33,31$, $30,29,18,25$, and $32,12,8$, respectively. To achieve drought-tolerant and high yielding genotypes, simultaneous selection of yield and yield stability can be used under nonstress and stress conditions, respectively. The results of this study indicated genotypes 34 and 29 had high yield stability under $75 \%$ FC with 0.880 and 0.888 , respectively and

Table 5. Average plant height $(\mathrm{cm})$, TKW thousand kernel weight $(\mathrm{g})$, grain yield $\left(\mathrm{kg} \mathrm{ha}^{-1}\right)$ and YSI (yield stability index) of 34 hexaploid wheat genotypes under non-stress and stress conditions

\begin{tabular}{|c|c|c|c|c|c|c|c|c|c|c|c|}
\hline \multirow{2}{*}{$\begin{array}{l}\text { Genotype } \\
\text { code }\end{array}$} & \multicolumn{3}{|c|}{ Plant height } & \multicolumn{3}{|c|}{ TKW } & \multicolumn{3}{|c|}{ Grain yield } & \multicolumn{2}{|c|}{ YSI } \\
\hline & $100 \% \mathrm{FC}$ & $75 \% \mathrm{FC}$ & $50 \% \mathrm{FC}$ & $100 \% \mathrm{FC}$ & $75 \% \mathrm{FC}$ & $50 \% \mathrm{FC}$ & $100 \% \mathrm{FC}$ & $75 \% \mathrm{FC}$ & $50 \% \quad \mathrm{FC}$ & $75 \% \mathrm{FC}$ & $50 \% \mathrm{FC}$ \\
\hline 1 & 87 & 86.3 & 83.6 & 37.88 & 28.51 & 24.3 & 5370.3 & 4112.43 & 3243.93 & 0.766 & 0.604 \\
\hline 2 & 95.3 & 77 & 84.3 & 33.43 & 31 & 26.63 & 6504.33 & 4937.5 & 3572 & 0.759 & 0.549 \\
\hline 3 & 85.6 & 72 & 68 & 37.6 & 33.61 & 30.48 & 4877.58 & 3808.87 & 3679.85 & 0.781 & 0.754 \\
\hline 4 & 85 & 80.6 & 80.6 & 37.05 & 33.41 & 32.63 & 4873.5 & 3760.8 & 3274.33 & 0.772 & 0.672 \\
\hline 5 & 82.6 & 69.3 & 66.6 & 37.75 & 35.11 & 31.23 & 6431.5 & 4243.33 & 3603.67 & 0.66 & 0.56 \\
\hline 6 & 139 & 125.3 & 113.3 & 40.76 & 34.4 & 33.01 & 6038.83 & 3970.62 & 3863.33 & 0.658 & 0.64 \\
\hline 7 & 132 & 127.3 & 129 & 43.3 & 32.91 & 32.83 & 7479.67 & 3990 & 3382.32 & 0.533 & 0.452 \\
\hline 8 & 120.3 & 118.3 & 118.3 & 37.46 & 29.01 & 26.7 & 6045.17 & 4067.58 & 2873.75 & 0.673 & 0.475 \\
\hline 9 & 131.6 & 131.3 & 118.3 & 29.15 & 27.68 & 28.56 & 4205.02 & 3733.5 & 3415.25 & 0.888 & 0.812 \\
\hline 10 & 120 & 122 & 128 & 39 & 31.86 & 24.31 & 4515.03 & 4019.45 & 3315.32 & 0.89 & 0.734 \\
\hline 11 & 153.3 & 139.3 & 133.6 & 37.41 & 32.1 & 28.51 & 6488.5 & 3825.33 & 3651.17 & 0.59 & 0.563 \\
\hline 12 & 131.6 & 131.3 & 123.6 & 33.98 & 31.33 & 25.56 & 6122.75 & 4816.5 & 2979.83 & 0.787 & 0.487 \\
\hline 13 & 143 & 127.6 & 124.3 & 34.05 & 31.16 & 27.26 & 6726 & 4041.3 & 4018.5 & 0.601 & 0.597 \\
\hline 14 & 120.6 & 125.3 & 114.3 & 35.1 & 32.85 & 30.33 & 5131.27 & 3847.5 & 3379.17 & 0.75 & 0.659 \\
\hline 15 & 122 & 111.3 & 115.3 & 35.05 & 33.35 & 30.41 & 7219.68 & 4173.67 & 3458.63 & 0.578 & 0.479 \\
\hline 16 & 120.3 & 117 & 112 & 43.08 & 34.58 & 30.5 & 4939.68 & 3698.67 & 3366.17 & 0.749 & 0.681 \\
\hline 17 & 123.6 & 120.6 & 108 & 38.55 & 32.91 & 31.13 & 5378.58 & 4006.15 & 3895 & 0.745 & 0.724 \\
\hline 18 & 130.6 & 131.3 & 126.3 & 40.6 & 32.76 & 26.61 & 6270 & 5085.67 & 4686.67 & 0.811 & 0.747 \\
\hline 19 & 116.6 & 111 & 94.3 & 38.68 & 34.23 & 34.38 & 5520.17 & 4240.17 & 3663.5 & 0.768 & 0.664 \\
\hline 20 & 132.3 & 124.6 & 119.3 & 46.18 & 37.56 & 31.28 & 5041.97 & 3945.67 & 3762 & 0.783 & 0.746 \\
\hline 21 & 110.3 & 111.3 & 110 & 38.48 & 35.06 & 27.36 & 6238.33 & 4037.5 & 4018.5 & 0.647 & 0.644 \\
\hline 22 & 115.6 & 108 & 109.3 & 39.38 & 32.81 & 29.71 & 6499.58 & 3841.17 & 3651.17 & 0.591 & 0.562 \\
\hline 23 & 94.6 & 91 & 95.6 & 41.65 & 34.5 & 31.45 & 6422.95 & 4819.67 & 3698.67 & 0.75 & 0.576 \\
\hline 24 & 110 & 104 & 100 & 37.36 & 31.66 & 25.85 & 5640.5 & 4166 & 3870.33 & 0.721 & 0.727 \\
\hline 25 & 95.3 & 91.6 & 91 & 37.76 & 33.83 & 29.1 & 5732.97 & 4491.92 & 4080.85 & 0.784 & 0.712 \\
\hline 26 & 71.3 & 66.3 & 66.3 & 36.8 & 32.51 & 30.11 & 7239.95 & 3919.07 & 3866.5 & 0.541 & 0.534 \\
\hline 27 & 81.6 & 83.3 & 77 & 35.56 & 31.35 & 29.81 & 8173 & 5595.5 & 4036.23 & 0.631 & 0.455 \\
\hline 28 & 82 & 71 & 67.3 & 44.51 & 34.16 & 31.75 & 6247.52 & 3421.58 & 3255.33 & 0.548 & 0.521 \\
\hline 29 & 80.6 & 81.3 & 74.6 & 39.5 & 36.73 & 28.88 & 6548.67 & 5765.07 & 5333.83 & 0.88 & 0.814 \\
\hline 30 & 80.6 & 82 & 81.3 & 41.83 & 34.51 & 30.85 & 8287.17 & 6903.33 & 5810.83 & 0.833 & 0.701 \\
\hline 31 & 79.3 & 70.3 & 65 & 36.73 & 32.6 & 30.38 & 6949.57 & 5864.67 & 5283.67 & 0.844 & 0.76 \\
\hline 32 & 95.3 & 89.3 & 86 & 37.38 & 31.13 & 26.98 & 7961 & 5291.5 & 3218.83 & 0.665 & 0.404 \\
\hline 33 & 80 & 87.3 & 83.6 & 35.4 & 30.88 & 27.41 & 7102.83 & 6156 & 4908.33 & 0.867 & 0.691 \\
\hline 34 & 99 & 94.3 & 89 & 40.48 & 33.6 & 32.63 & 6640.5 & 5899.5 & 5148.17 & 0.888 & 0.775 \\
\hline LSD (5\%) & & 16.194 & & & 6.726 & & & 260.856 & & & \\
\hline
\end{tabular}


272

under 50\% FC, 0.814 and 0.775 , respectively. In addition, these genotypes showed high yield under non-stress condition and therefore, they were classified as tolerant. Concerning this index, maintaining grain yield potential under water stress can be considered as a physiological criterion for drought tolerance. In this context, genotypes with a high percentage of grain yield reduction under stress conditions can be categorized as susceptible. Alternatively, the combination of yield under both stress and non-stress conditions can be considered as a criterion for drought tolerance (Sio-se Mardeh et al., 2006). Genotypes 34, 31, 30, 29 , and 25 produced relatively high yields under both conditions of stress and non-stress (Table 5). Moreover, they had high yield stability in comparison to the others. Genotypes 32,12 and 8 which showed a higher yield reduction under drought stress, had lower yield stability than the others (Table 5). The negative effect of drought stress as a major problem on yield has been well documented in many studies worldwide (Passioura, 2007). However, investigating different traits including genotypes' relative yield under stress and non-stress conditions would be a starting point to understand the drought tolerance process and choose genotypes for breeding in dry environments.

\section{Drought susceptibility index}

Relative drought tolerance, i.e. drought susceptibility index (DSI) of genotypes, was calculated based on grain yield/plant as given in Fig. 2. DSI values ranged from 0.40 to 1.71 under $75 \% \mathrm{FC}$ and 0.30 to 0.97 under $50 \% \mathrm{FC}$. Genotypes with a DSI less than 1.0 were considered as drought tolerant and those above 1.0 were regarded as drought susceptible (Guttieri et al., 2001). Based on DSI, genotypes $31,20,17,10,9$ and 3 were tolerant and genotypes 26, 15, 13 and 8 were sensitive. Similarly, Dorostkar et al. (2015) reported that genotypes with DSI less than 1, produced high yield under both stress and nonstress conditions and consequently showed high yield potential. Therefore, DSI is a suitable index for selecting genotypes under stress conditions.

\section{Antioxidant enzyme activity}

In the present study, SOD activity was recorded under stress and non-stress conditions. The results showed that drought stress affected the activity of this enzyme significantly (Fig. 3). The SOD increase was higher in tolerant genotypes than in sensitive ones. The highest and lowest amounts of SOD belonged to genotypes 14, 17 and 19,30 under normal condition, while genotypes 22,19 and 27,31 under $75 \%$ FC had the highest and lowest activities, respectively. The genotypes 29,30 and 15, 28 had highest and lowest figures under 50\% FC, respectively. The high activity of superoxide dismutase in genotype 29 under severe drought indicates that this genotype has high tolerance to stress which is reflected in its high yield under stress conditions with good yield stability (Table 5), possibly an indication of SOD efficiency in altering $\mathrm{O}_{2}$ to $\mathrm{H}_{2} \mathrm{O}_{2}$. Similar results were obtained by Apel and Hertz (2004), Shao et al. (2005), Wang et al. (2010) and Dorostkar et al. (2016) who reported that superoxide dismutase as one of the most important antioxidants had higher production in wheat drought tolerant genotypes. Since superoxide dismutase converts super-oxygen to hydrogen peroxide which is in turn removed by other antioxidants, increase in this enzyme's activity should be accompanied with production of other antioxidants.

Likewise, peroxidase (POD) activity increased significantly under drought stress (Fig. 3). Its increase in tolerant genotypes was more pronounced than sensitive ones. Under normal condition, the genotypes 34, 33, 27 and 12 had the lowest amount of this enzyme while the highest activity belonged to genotypes 29,22, 19 and 11. Under $75 \%$ FC, the highest and lowest levels of peroxidase belonged to genotypes 29,19 and 10, 12, respectively. Also, under 50\% FC stress conditions, the least amount was detected in sensitive genotypes; 32 and 8 and the highest was produced in genotypes 29 and 19 . As mentioned earlier, POD is another key enzyme that reduces the amount of $\mathrm{H}_{2} \mathrm{O}_{2}$ produced in chloroplasts. Therefore, its concentration is always higher in tolerant genotypes (Asada, 1992; Sarvajeet and Narendra, 2010; Wang et al., 2010; Pourtaghi et al., 2011). Several studies have reported that peroxidase activity increases greatly in response to water stress in wheat (Zhang and Kirkham, 1994; KhannaChopra and Selote, 2007). Similarly, in the industrial crop; Nicotiana tabacum, higher peroxidase activity was shown to be associated with higher water retention (Mercado et al., 2004).

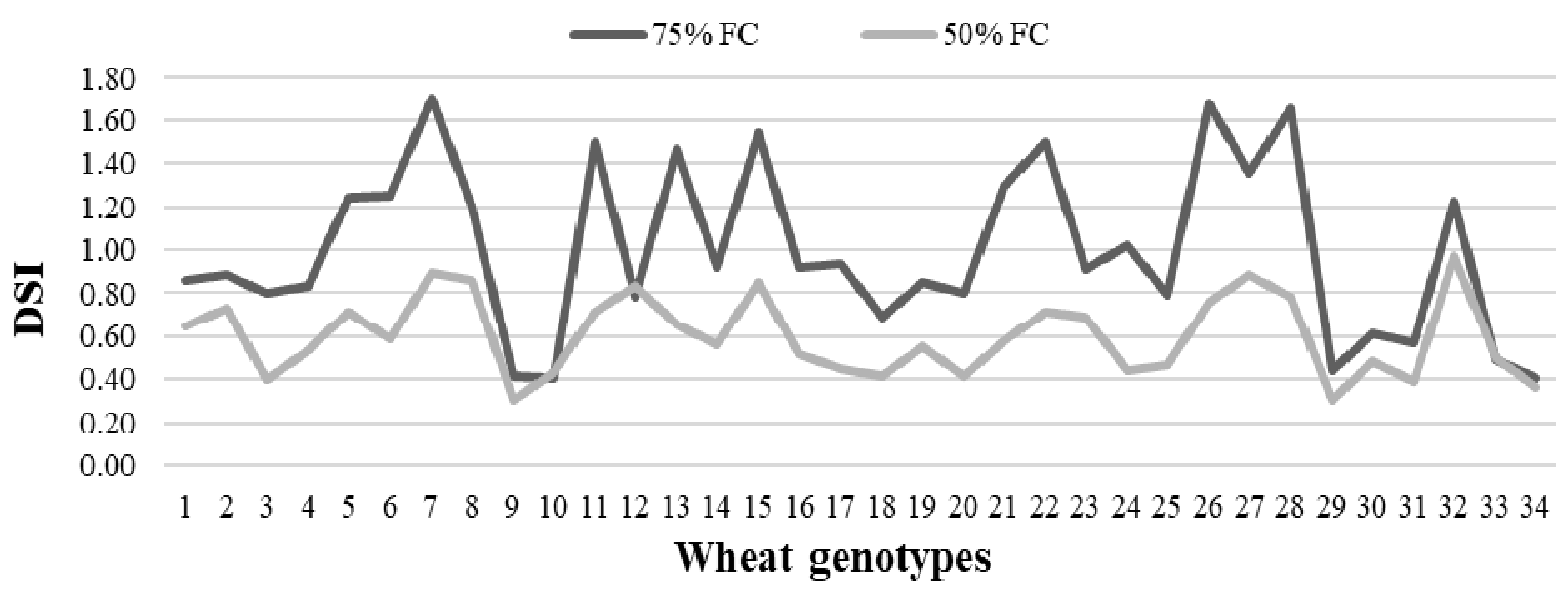

Fig. 2. Drought susceptibility index (DSI) of thirty-four wheat genotypes under different levels of water deficit stress 
This means genotypes maintaining higher peroxidase activity in leaves under water stress may also have higher water retention and subsequently tolerate stress.

Similarly, drought stress increased catalase (CAT) activity in the studied genotypes, and this increase was more pronounced in tolerant genotypes (Fig. 3). For example, in genotype 23, CAT increased more than twice, while in genotype 32 , only $30 \%$ increase was detected compared to normal irrigation conditions. Genotypes 15 and 10 had the highest and the genotypes 8 and 7 had the lowest CAT activity under non-stress condition. Genotype 29 showed the highest CAT activity under both $75 \%$ and $50 \%$ FC conditions. Environmental stresses especially abiotic ones increase the production of active oxygen species such as superoxide $\left(\mathrm{O}_{2}\right)$ and hydrogen peroxide $\left(\mathrm{H}_{2} \mathrm{O}_{2}\right)$ in plants, which leads to lipid peroxidation and cell death. Catalase is one of the enzymes plants produce when various types of $\mathrm{O}_{2}$ expose them to drought stress in order to reduce the damage caused. Antioxidant enzymes such as catalase have largely contributed to plants' tolerance to drought stress due to the removal of free oxygen radicals (Apel and Hirt, 2004; Shao et al., 2005; Asada and Takahashi, 2006; Wang et al., 2010). Since both catalase and peroxidase function as detoxifying $\mathrm{H}_{2} \mathrm{O}_{2}$, catalase activity can be compensated by increase in peroxidase activity in tolerant cultivars. Under drought stress, an increase in peroxidase activity has been earlier reported in wheat (Devi et al., 2012; Valifard et al., 2012). Conversely, a decreased catalase activity with a simultaneous increase in peroxidase activity under heat stress has been reported in leaves and roots of creeping bentgrass (Liu and Huang, 2000).

The wheat genotypes responded differently to water stress in terms of activities of SOD, CAT and POX. SOD and POX had higher expression in tolerant genotypes than sensitive ones. This further suggests that different wheat genotypes have discrete water stress thresholds and therefore they have different physiological adaptive mechanisms to regulate their redox status (Shao et al., 2005).

\section{Proline content}

Proline showed a significant increase in all genotypes under water deficit conditions compared to controls, i.e Shiraz and Bezostaya (Fig. 4). Under normal irrigation conditions, the highest amount of proline belonged to genotypes 32,29,27, 25, 20 and 13 and the lowest accumulation was observed in genotypes $34,30,22,18,15$, 11 and 8 . Under $75 \%$ FC condition, the highest and lowest proline content, belonged to 34, 31, 29, 25, 19, 13, 6 and 32, $24,22,21,17,11,8$ respectively. Under $50 \%$ FC, the proline content increased more than that of $75 \% \mathrm{FC}$ and genotypes 34, 31, 29, 25, 24, 22, 19 and 3 had the highest while genotypes $33,32,18,17,11$ and 1 had the lowest amount of proline (Fig. 4).

The data showed that proline content was higher in tolerant genotypes than susceptible ones under stress conditions (Fig. 4). Proline increase under stress conditions helps to protect cells by balancing the osmotic pressure of cytoplasm as well as the vacuoles and the surrounding environment. In addition to preserving the osmotic balance of cytoplasm, proline affects cellular macromolecules such as enzymes and leads to the stability of their structure and function (Shimshi et al., 1982). Also, genotypes with higher proline content under stress conditions produce a relatively higher yield. Some researchers believe that proline accumulation in plants under drought stress, acts as a compatible solute and serves as a source of nitrogen and carbon, while others maintain the view that proline protects the protoplasm against drought. These results are consistent with those of Pireivatloum et al. (2010) and Dorostkar et al. (2016) who showed that drought stress increased proline accumulation significantly in different stages of growth of wheat.

\section{Similarity of genotypes with respect to traits}

The tree dendrogarm showing similarities between tested genotypes is displayed in Fig. 5. In this analysis, the highest similarity was observed between genotypes 22 and 11 with a distance of 0.0059 while the lowest similarity distance belonged to genotypes 27 and 30 .

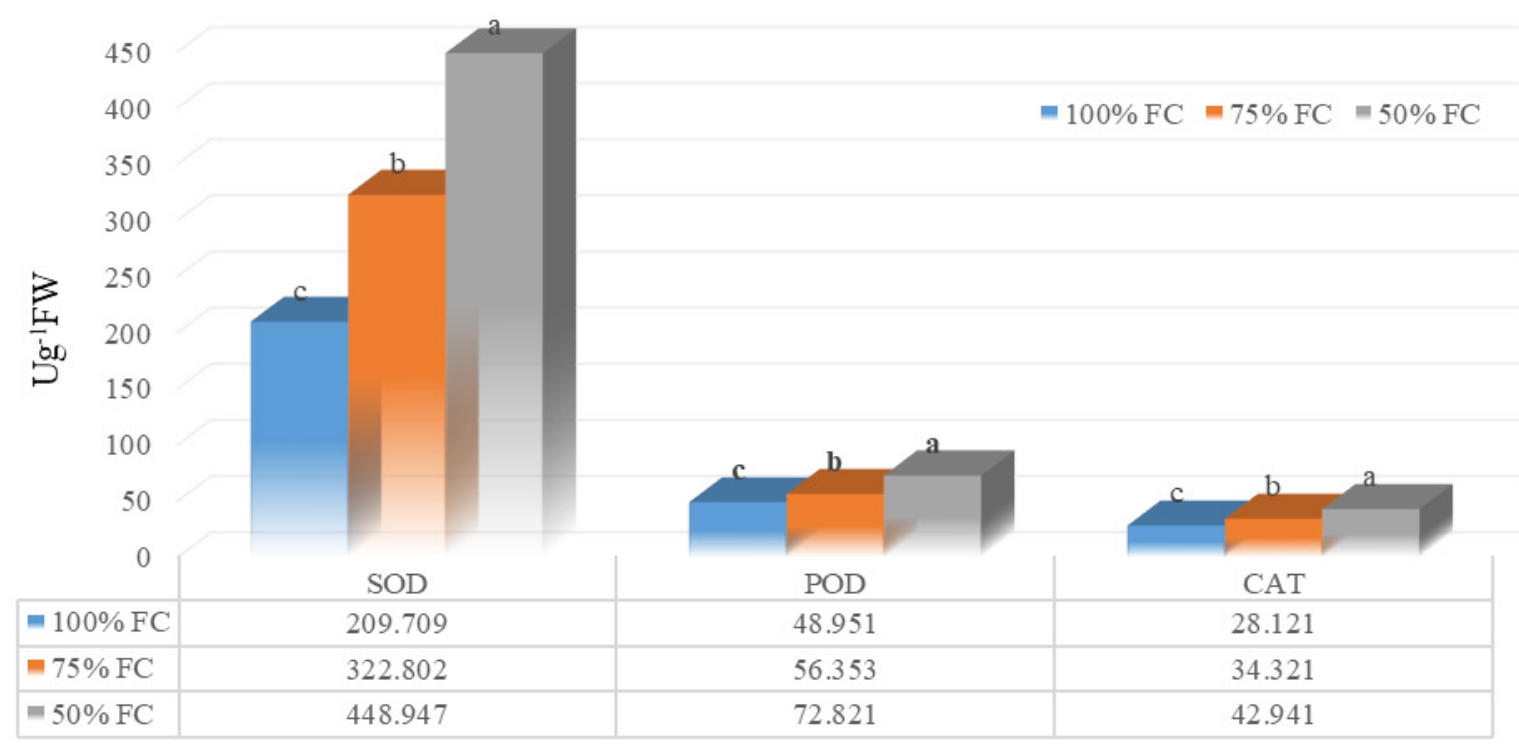

Fig. 3. Changes in the enzymatic activities (Superoxide dismutase (SOD), peroxidase (POD) and catalase (CAT)) for thirty-four genotypes under stress and non-stress conditions in $\mathrm{Ug}^{-1} \mathrm{FW}$ (Units $\mathrm{g}^{-1}$ fresh weight). Different letters indicate significant differences. FC stands for field capacity 
274

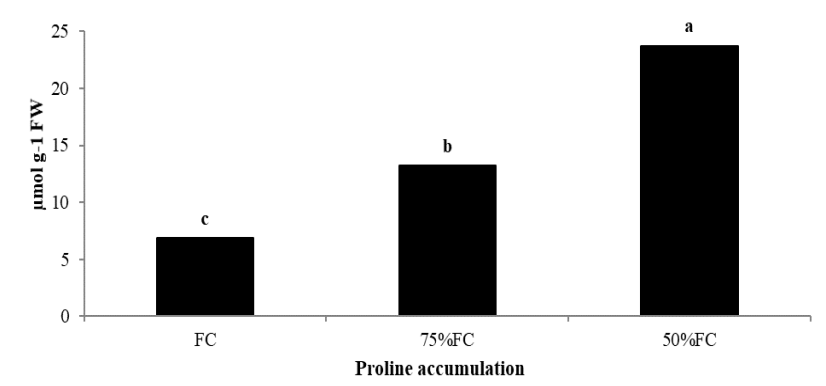

Fig. 4. Variation in proline content under water stress (75 and $50 \%$ FC) and non-stress (FC) conditions. FC: field capacity. Different letters indicate significant differences at $\mathrm{LSD}_{5 \%}$

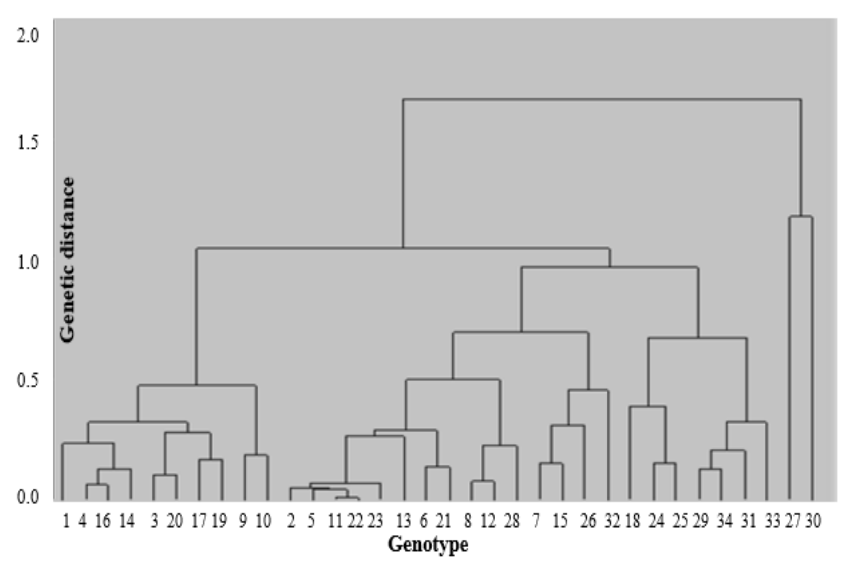

Fig. 5. Tree dendrogram of 34 wheat genotypes

Genotypes 22 and 11 were Iranian landraces and genotypes 27 and 30 were from CIMMYT. The genotypes 29, 31, 33, 34, 18, 24 and 25, which were classified as tolerant based on the measured indices in this experiment, were grouped in one cluster. These genotypes could be useful for stress conditions. The other group, consisted of genotypes 7 and 32 were sensitive to drought based on studied characteristics and belonged to one cluster. These genotypes are not suitable for water deficit environment.

In this figure, the group consisting of genotypes $1,4,16$, $14,3,20,17,19,9$ and 10 had the highest grain yield under non-stress condition while showed high yield loss under stress conditions (75\% FC and 50\% FC). Genotypes 2, 5, $11,22,23,13,28,12,8,6$ and 21 were grouped in a cluster which had moderate grain yield under both stress and nonstress conditions except genotypes 28 and 8 that showed the lowest grain yield under 75\% FC and 50\% FC conditions, respectively. In addition, in this group, genotype 13 had higher yield than the others. The cluster comprised of genotypes 32, 26, 15 and 7 had high yield under normal condition while had the lowest yield stability. Genotypes 18, 24, 25, 29, 34, 31 and 33 showed lower grain yield loss under both 75\% FC and 50\% FC conditions and consequently had high yield stability. The highest grain yield belonged to genotypes 27 and 30 under normal condition. Genotype 30 ranked first in terms of yield under $75 \%$ FC and 50\% FC conditions, showed high yield stability, and therefore is suitable for stress conditions while genotype 27 had high yield loss showing susceptibility to water stress conditions.

\section{Conclusions}

Oxidative damage is an important factor that could decrease plant yield. Drought tolerant genotypes in current study showed higher RWC compared to controls, however, the fact that the activity of any antioxidant enzyme cycle was superior to that of the control may be indicative of cultivar stability. Our results indicated that drought tolerant wheat genotypes had higher enzymes activities and higher proline content than drought sensitive ones, protecting themselves more efficiently under drought stress. Of biochemical enzymes, superoxide dismutase had higher ability to detect tolerant and sensitive genotypes, because this enzyme had a significantly higher activity in tolerant genotypes than sensitive ones under drought stress conditions. Based on the results, the high yielding genotypes under normal, 75\% FC and 50\% FC conditions were 27 , 30,32 and 30, 33, 24, 29 and 18, 25, 29, 30, 31, 33, 34, respectively. In general, genotypes $24,25,29,30,31,34$ were categorized as tolerant and 7,27, 32 ranked as sensitive due to measured indices. These tolerant genotypes, 25 ('Akbari'), 29 ('30ESWYT173') and 31 ('30ESWYT200') are of great value for potential use in breeding programs.

\section{Acknowledgements}

The first author would like to thank the Department of Crop Production and Plant Breeding, School of Agriculture, Shiraz University for supporting him during MSc studies.

\section{Conflict of Interest}

The authors declare that there are no conflicts of interest related to this article.

\section{References}

Almeselmani M, Abdullah F, Hareri F, Naaesan M, Ammar MA, Kanbar OZ, Saud AA (2011). Effect of drought on different physiological characters and yield component in different varieties of Syrian durum wheat.Journal of Agricultural Science 3(3):127-133.

Almeselmani M, Deshmukh PS, Sairam RK, Kushwaha SR, Singh TP (2006). Protective role of antioxidant enzymes under high temperature stress. Plant Science 171(3):382-388.

Apel K, Hirt H (2004). Reactive oxygen species: metabolism, oxidative stress, and signal transduction. Annual Review of Plant Biology 55:373-399.

Asada K (1992). Ascorbate peroxidase-a hydrogen peroxide-scavenging enzyme in plants. Physiologia Plantarum 85(2):235-241.

Asada K, Takahashi M (2006). Production and scavenging of active oxygen in photosynthesis. Physiologia Plantarum 141:391-405.

Bartosz G (1997). Oxidative stress in plants. Acta Physiologia Plantrum 19(1):47-64.

Bates LS, Waldren RP, Teare ID (1973). Rapid determination of free proline for water-stress studies. Plant and Soil 39(1):205-207.

Beauchamp C, Fridovich I (1971). Superoxide dismutase: improved assays and an assay applicable to acrylamide gels. Analytical Biochemistry 44(1):276-287. 
Bouslama M, Schapaugh WT (1984). Stress tolerance in soybeans. I. Evaluation of three screening techniques for heat and drought tolerance 1. CropScience 24(5):933-937.

Castrillo M, Calcagno AM (1989). Effects of water stress and re watering on ribulose-1, 5-bis-phosphate carboxylase activity, chlorophyll and protein contents in two cultivars of tomato. Journal of Horticultural Science 64(6):717-724.

Chance B, Maehly AC (1995). Assay of catalase and peroxidase. Journal of Plant Physiology 2:764791.

$\mathrm{DaCosta} \mathrm{M}, \mathrm{Huang} \mathrm{B}$ (2007). Changes in antioxidant enzyme activities and lipid peroxidation for bentgrass species in response to drought stress. Journal of the American Society for Horticultural Science 132(3):319326.

De Carvalho MHC (2008). Drought stress and reactive oxygen species: production, scavenging and signaling. Plant Signaling and Behavior 3:156-165.

Devi R, Kaur N, Gupta, AK (2012). Potential of antioxidant enzymes in depicting drought tolerance of wheat (Triticum aestivum L.). Indian Journal of Biochemistry and Biophysics 49:257-265.

Dorostkar S, Dadkhodaie A, Heidari B (2015). Evaluation of grain yield indices in hexaploid wheat genotypes in response to drought stress. Archives of Agronomy and Soil Science 61(3):397-413.

Dorostkar S, Dadkhodaie A, Heidari B (2016). Changes in biochemical characteristics of thirty-six Iranian wheat landraces in response to drought stress and their classification using multivariate analysis. Journal of Animal and Plant Science 26(6):1740-1749.

Ehdaie B, Alloush GA, Waines JG (2008). Genotypic variation in linear rate of grain growth and contribution of stem reserves to grain yield in wheat. Field Crops Research 106(1):3443.

Emam Y,NikNejad M (1994). An introduction to physiology of cropyield. Shiraz, Shiraz University Press [in Persian].

FAOSTAT(2017).http://faostat.fao.org/site/339/defaultaspx.

Fischer RA, Maurer R(1978). Drought resistance in spring wheat cultivars. I. Grain yield responses. Australian Journal of Agricultural Research 29(5):897-912.

González A, Martin I, Ayerbe L (1999). Barley yield in water-stress conditions: The influence of precocity, osmotic adjustment and stomatal conductance. Field Crops Research 62(1):23-34.

Guttieri MJ, Stark JC, O'Brien K, Souza E (2001). Relative sensitivity of spring wheat grain yield and quality parameters to moisture deficit. Crop Science 41(2):327-335.

Hall AJ, Richards RA (2013). Prognosis for genetic improvement of yield potential and water-limited yield of major grain crops. Field Crops Research 143:18-33.

Hendry GAF, Price AH (1993). Stress indicators: chlorophylls and carotenoids. Chapman \& Hall,London.

Keyvan S (2010). The effects of drought stress on yield, relative water content, proline, soluble carbohydrates and chlorophyll of bread wheat cultivars. Journal of Animal and Plant Sciences 8(3):1051-1060.

Khanna-Chopra R, Selote DS (2007). Acclimation to drought stress generates oxidative stress tolerance in drought-resistant than-susceptible wheat cultivar under field conditions. Environmental and Experimental Botany 60(2):276-283.
Kirigwi FM, van Ginkel M, Trethowan R, Sears RG, Rajaram S, Paulsen GM (2004). Evaluation of selection strategies for wheat adaptation across water regimes. Euphytica 135(3):361-371.

Lichtenthaler H, Wellburn AR (1983). Determination of total carotenoids and chlorophyll a and chlorophyll b leaf extracts in different solvents. Biochemical Society Transactions 11:591-592.

Liu X, Huang B (2000). Heat stress injury in relation to membrane lipid peroxidation in creeping bentgrass. CropScience 40(2):503-510.

Mercado JA, Matas AJ, Heredia A, Valpuesta V, Quesada MA (2004). Changes in the water binding characteristics of the cell walls from transgenic Nicotiana tabacum leaves with enhanced levels of peroxidase activity. Physiologia Plantarum 122(4):504512.

Mitra J (2001). Genetics and genetic improvement of drought resistance in crop plants. Current Science 80:758-763.

Mittler R (2006). Abiotic stress, the field environment and stress combination. Trends in Plant Science 11(1):15-19.

Nyachiro JM, Briggs KG, Hoddinott J, Johnson-Flanagan AM (2001). Chlorophyll content, chlorophyll fluorescence and water deficit in springwheat. Cereal Research Communications 29:135-142.

Passioura J (2007). The drought environment: physical, biological and agricultural perspectives. Journal of Experimental Botany 58(2):113117.

Pireivatloum J, Qasimov N, Maralian H (2010). Effect of soil water stress on yield and proline content of four wheat lines. African Journal of Biotechnology 9(1):36-40.

Pourtaghi A, Darvish F, Habibi D, Nourmohammadi G, Daneshian J (2011). Effect of irrigation water deficit on antioxidant activity and yield of some sunflower hybrids. Australian Journal of Crop Science 5(2):197-204.

Rao L, Perez D, White E (1996). Lamin proteolysis facilitates nuclear events duringapoptosis.Journal of Cell Biology 135(6):1441-1455.

Saini HS, Westgate ME (2000). Reproductive development in grain crops duringdrought. Advances in Agronomy 68:59-95.

Sairam RK, Deshmukh PS, Shukla DS (1997). Tolerance of drought and temperature stress in relation to increased antioxidant enzyme activity in wheat.Journal of Agronomy and CropScience 178(3):171-178.

Sairam RK, Saxena DC (2000). Oxidative stress and antioxidants in wheat genotypes: possible mechanism of water stress tolerance. Journal of Agronomy and CropScience 184(1):55-61.

Sairam RK, Srivastava GC (2001). Water stress tolerance of wheat (Triticum aestivum L.): variations in hydrogen peroxide accumulation and antioxidant activity in tolerant and susceptible genotypes. Journal of Agronomy and CropScience 186(1):63-70.

Sarvajeet SG, Narendra T (2010). Reactive oxygen species and antioxidant machinery in abiotic stress tolerance in crop plants. Plant Physiology and Biochemistry 48(2):909-930.

SAS. 2004. SAS version 9.2. Cary (NC): SAS Institute Inc. SAS Online Doc 913.

Schonfeld M,Johnson R, Carver B, MornhinwegD (1988). Water relations in winter wheat as drought resistant indicators. Crop Science 28(3):526531.

Shao HB, Liang ZS, Shao MA, Sun Q (2005). Dynamic changes of antioxidative enzymes of 10 wheat genotypes at soil water deficits. Colloids 
276

and Surfaces B: Biointerfaces 42(3-4):187-195.

Sheoran S, Pandey B, Sharma P, Narwal S, Singh R, Sharma I, Chatrath R (2013). In silico comparative analysis and expression profile of antioxidant proteins in plants. Genetics and Molecular Research 12(1):537-551.

Sheoran S, Thakur V, Narwal S, Turan R, Mamrutha HM, Singh V, Sharma I (2015). Differential activity and expression profile of antioxidant enzymes and physiological changes in wheat (Triticum aestivum L.) under drought. Applied Biochemistry and Biotechnology 177(6):1282-1298.

Shimshi D, Mayoral M, Atsmon D (1982). Responses to water stress in wheat and related wild species. CropScience 22(1):123-128.

Shinozaki K, Yamaguchi-Shinozaki K (2007). Gene networks involved in drought stress response and tolerance. Journal of Experimental Botany 58(2):221-227.
Sio-se Mardeh A, Ahmadi A, Poustini K, Mohammadi V (2006). Evaluation of drought resistance indices under various environmental conditions. Field Crops Research 98(2-3):222-229.

Valifard M, Moradshahi A, Kholdebarin B (2012). Biochemical and physiological responses of two wheat (Triticum aestivum $\mathrm{L}$.) cultivars to drought stress applied at seedling stage. Journal of Agriculture Science and Technology 14:1567-1578.

Wang HZ, Zhang LH, Jun MA, Li XY, Yan LI, Zhang RP, Wang RQ (2010). Effects of water stress on reactive oxygen species generation and protection system in rice during grain-filling stage. Agricultural Sciences in China 9(5):633-641.

Zhang J, Kirkham MB (1994). Drought stress-induced changes in activities of superoxide dismutase, catalase and peroxidase in wheat species. Plant and Cell Physiology 35(5):785-791.

Zimmerman JD (2002). Irrigation. New York,John Wiley \& Sons Inc. 